\title{
Perifoveal microcirculation in eyes with epiretinal membranes
}

\author{
Kazuaki Kadonosono, Norihiko Itoh, Eiichi Nomura, Shigeaki Ohno
}

\begin{abstract}
Backgroundlaims-Eyes with epiretinal membranes (ERMs) often have alterations of retinal vessels. The authors studied perifoveal microcirculation in eyes with epiretinal membranes (ERMs) using scanning laser ophthalmoscope (SLO) fluorescein angiography.

Methods-Mean capillary blood flow velocity (CFV) was measured as an index of perifoveal microcirculation by SLO fluorescein angiography in 26 eyes with ERMs (19 eyes with idiopathic epiretinal membranes, seven eyes with epiretinal membranes after retinal detachment surgery) before and 6 months after vitreous surgery, and in 23 healthy control subjects.

Results-The mean CFV was significantly reduced in eyes with ERMs compared with healthy controls $(p=0.012)$, and the postoperative mean CFV was significantly increased compared with the preoperative mean CFV $(p=0.041)$.

Conclusion-Significant changes of capillary blood flow velocity in the perifoveal areas were observed between normal subjects and eyes with epiretinal membranes. This indicates that eyes with ERMs show abnormal haemodynamics in the perifoveal capillaries.

(Br f Ophthalmol 1999;83:1329-1331)
\end{abstract}

Epiretinal membranes (ERMs) are frequently observed in association with a variety of ocular diseases, retinal detachment surgery, and other eye surgeries. However, most ERMs are independent of these specific diseases and can be termed idiopathic. ${ }^{12}$

In all aetiologies of epiretinal membranes, they have only a minor or no effect on vision. However, in the milder cases, the membranes become thickened and contracted. The perifoveal capillary vessels also become increasingly tortuous, although the major vessels remain almost normal. ${ }^{3}$ As the disease progresses, the major vessels become dilated and tortuous mostly because of the tangential traction applied by the membranes, ${ }^{4-8}$ resulting in macular oedema, which is associated with clinical macular oedema and angiographic leakage. ${ }^{9}$

These retinal vascular changes in eyes with ERMs may damage the retinal vasculature leading to disturbances in the haemodynamics of the affected areas. However, there have not been any reports on ocular circulation and no quantitative studies on macular capillary blood flow velocity in eyes with epiretinal membranes. We quantified the retinal blood flow velocity in the macular capillaries of eyes with ERMs to determine whether the perifoveal blood flow velocity in eyes with ERMs can be altered and improved by vitreous surgery.

In this study, we measured the perifoveal capillary blood flow velocity (CFV) in eyes with ERMs by fluorescein angiography using a scanning laser ophthalmoscope (SLO), and compared the data with those obtained from control subjects and postoperative data.

\section{Materials and methods}

Twenty six eyes of 26 consecutive patients with epiretinal membranes who underwent vitrectomy from January 1996 to the end of February 1998 were studied. Nineteen eyes of 19 patients had idiopathic epiretinal membranes, and seven eyes of seven patients had secondary epiretinal membranes after retinal detachment surgery. Patients with cataracts, other ocular diseases, or systemic disease involving the circulation were excluded. All 26 patients had been referred for management of epiretinal membranes and were being followed in a prospective manner. Epiretinal membranes were examined under slit lamp biomicroscopy with contact lens. The extent and thickness were determined using SLO (Rodenstock Instrument, Munich, Germany). Either argon blue $(488 \mathrm{~nm})$ or argon green $(514 \mathrm{~nm})$ laser illumination was used during the SLO examination (Fig 1).

An almost equal number of age matched normal subjects served as the control group. Video fluorescein angiography with the SLO was performed in eyes with ERMs, preoperatively and 6 months postoperatively. Complete
Figure 1 The fundus image in a patient with ERMs by argon blue laser using SLO. The formation of well defined membrane involving the macula is seen. This membrane is associated with retinal fold and distortion of the adjacent retinal vessels. 


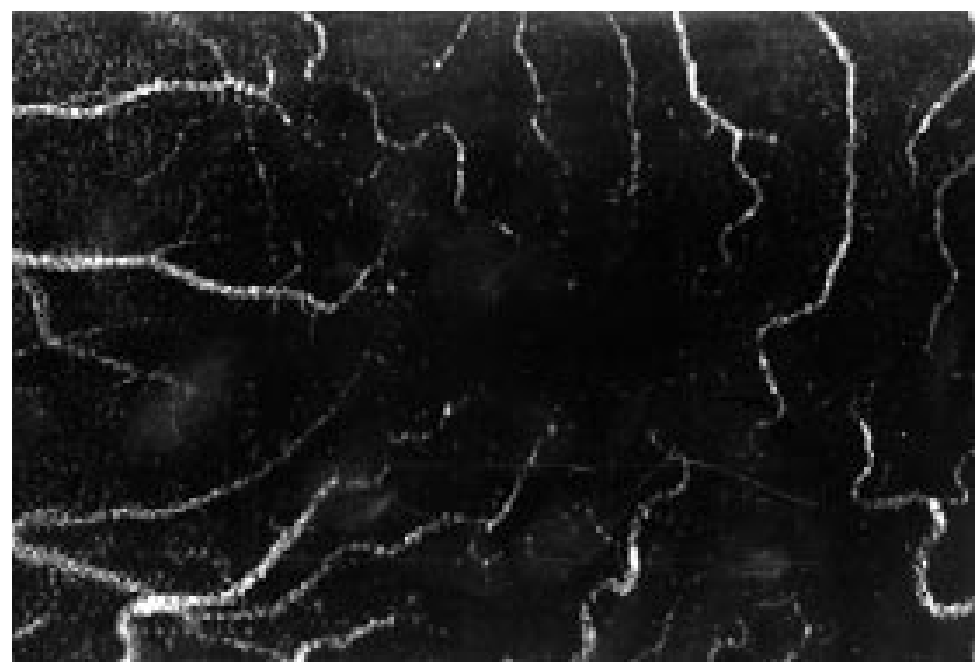

Figure 2 Digital fluorescein angiogram of the perifoveal network in the same patient as in Figure 1. Tortuosity of capillary vessels are seen.

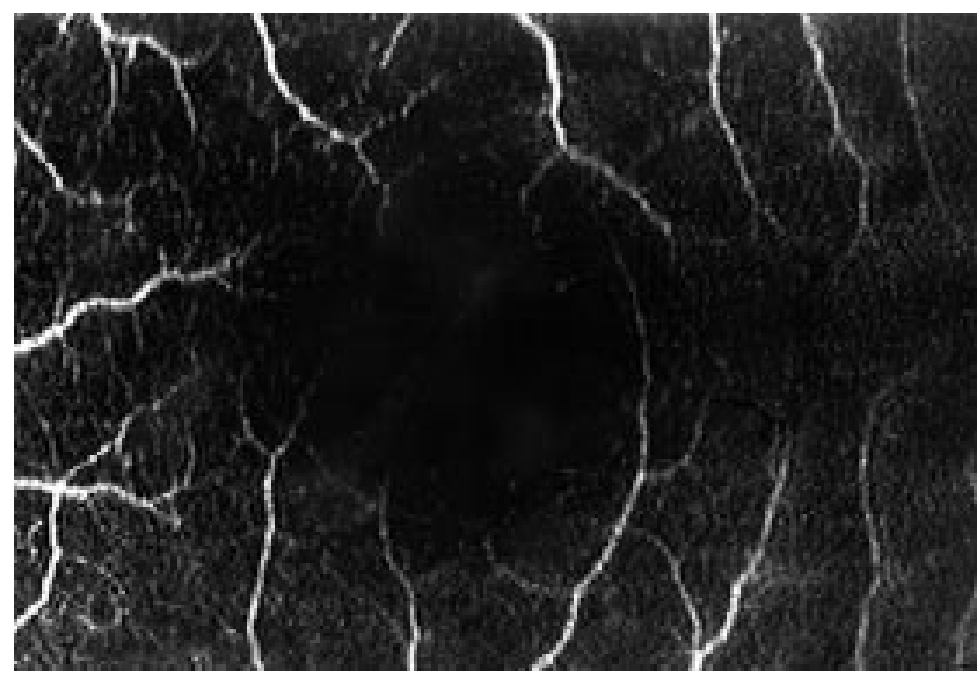

Figure 3 Postoperative digital fluorescein angiogram of the perifoveal network in the same patient as in Figure 1. The capillary vessels have assumed almost normal configuration.

clinical examination results, including best corrected visual acuity, were recorded at the final visit.

The technique for vitreous surgery consisted of standard pars plana vitrectomy. The epiretinal membrane was peeled with a microhooked needle after simple vitrectomy, and the peeled membrane was held and removed with vitreous forceps. An air tamponade was conducted postoperatively, and the patients were instructed to assume the prone position for several days.

The measurement technique with the scanning laser ophthalmoscope introduced by Wolf and associate ${ }^{10}$ enables assessment of capillary blood flow velocity. The perifoveal capillary blood velocity was assessed in the perimacular region by tracking the movement of a hypofluorescent front through a capillary per frame (20 degree field). Measurement of the blood flow velocity in the perifoveal network of capillaries was calculated off line by frame to frame analysis on the basis of the blood transit time between two points separated by a known distance. The compression of the vessel may have affected the calculation of distance. All values
Table 1 Characteristics of study participants

\begin{tabular}{lllll}
\hline & $\begin{array}{l}\text { Patients } \\
\text { with ERMs }\end{array}$ & $\begin{array}{l}\text { (Idiopathic } \\
\text { ERMs) }\end{array}$ & $\begin{array}{l}\text { (Secondary } \\
\text { ERMs) }\end{array}$ & $\begin{array}{l}\text { Control } \\
\text { patients }\end{array}$ \\
\hline Sex M/F & $14 / 12$ & $(9 / 10)$ & $(5 / 2)$ & $13 / 10$ \\
Age & 54.2 & $(53.2)$ & $(56.3)$ & 46.0 \\
Eye R/L & $9 / 17$ & $(6 / 13)$ & $(3 / 4)$ & $11 / 12$ \\
\hline
\end{tabular}

Table 2 Perifoveal capillary blood flow velocity (CFV) of the patients with ERMs and control patients

\begin{tabular}{llll}
\hline & $\begin{array}{l}\text { Patients with } \\
\text { ERMs } \\
\text { Mean (SD) }\end{array}$ & $\begin{array}{l}\text { Control } \\
\text { patients } \\
\text { Mean (SD) }\end{array}$ & p Value \\
\hline $\mathrm{CFV}(\mathrm{mm} / \mathrm{s})$ & $2.90(0.27)$ & $3.33(0.09)$ & 0.012 \\
\hline
\end{tabular}

Table 3 Perifoveal capillary blood flow (CFV) of the patients with ERMs before and 6 months after surgery

\begin{tabular}{llll}
\hline & $\begin{array}{l}\text { Before surgery } \\
\text { Mean (SD) }\end{array}$ & $\begin{array}{l}\text { Six months } \\
\text { after surgery } \\
\text { Mean (SD) }\end{array}$ & p Value \\
\hline $\mathrm{CFV}(\mathrm{mm} / \mathrm{s})$ & $2.90(0.27)$ & $3.09(0.71)$ & 0.041 \\
\hline
\end{tabular}

of the mean blood flow velocity were the result of 100 single measurements in the eye with ERM before and after vitreous surgery (Figs 2, 3). All results were corrected for magnification using axial lengths and keratometry according to the Littmann formula. ${ }^{11} 12$

\section{Results}

The subjects included 14 men and 12 women with a mean age of 54.2 years (see Table 1 ). The mean follow up period was 6.9 months (range 6-9 months). Among the 26 eyes assessed, visual acuity at 6 months postoperatively had improved by two or more lines in 17 eyes $(65 \%)$, worsened by two or more lines in none $(0 \%)$, and remained unchanged in nine eyes $(35 \%)$. Seven eyes $(27 \%)$ attained a final visual acuity of $20 / 40$ or better. Eighteen eyes $(69 \%)$ had a final visual acuity of $20 / 200$ or better and one eye (4\%) had a final visual acuity of less than $20 / 400$.

The preoperative mean $\mathrm{CFV}$ in eyes with ERMs was 2.90 (SD 0.27) $\mathrm{m} / \mathrm{s}$, as opposed to $3.31(0.09) \mathrm{m} / \mathrm{s}$ in the control eyes without ERM (see Table 2). The mean CFV in eyes with ERMs was significantly lower than that in control subjects ( $p=0.012$, using the MannWhitney U test).

The postoperative mean $\mathrm{CFV}$ in eyes with ERMs was $3.09(0.71) \mathrm{m} / \mathrm{s}$. The mean CFV in eyes with ERMs increased significantly postoperatively $(\mathrm{p}=0.041$, using the Mann-Whitney U test) (see Table 3). Less tortuosity of capillary vessels was seen postoperatively and the mean CFV was increased in all eyes. Metamorphopsia decreased in all patients. Seven eyes that had not undergone cataract surgery developed progressive nuclear sclerosis. Three eyes in which the microhooked needle inadvertently struck the perifovea during the membrane peeling developed retinal pigment cell atrophy postoperatively, but the visual acuity remained at the preoperative level.

\section{Discussion}

Epiretinal membranes occurring without any ocular condition or surgical procedure are 
termed idiopathic. However, epiretinal membranes may also develop after several surgical procedures. In particular, epiretinal membranes are often observed after retinal detachment surgery, commonly referred to as macular pucker. ${ }^{13}$ In this study we assessed these 26 eyes with epiretinal membranes (19 eyes with idiopathic epiretinal membranes, seven eyes with secondary epiretinal membranes after retinal detachment surgery) to determine the capillary blood flow velocity using an imaging technique with SLO fluorescein angiography.

This study revealed that the capillary blood flow velocity was lower in eyes with ERMs than in normal eyes. As these ERMs slowly contract and lift the retinal surface, the foveal capillary network becomes tortuous and compressed. Tangential traction acting on the retinal surface causes architectural changes in the retinal vessels. These alterations to the vasculature may induce the haemodynamic disturbances of the microcirculation in eyes with ERMs.

Moreover, the reduction in the capillary blood flow velocity in eyes with epiretinal membranes may be due to morphological changes of the capillary beds such as changes in endothelial cells. Unlike eyes affected by diabetic retinopathy, ${ }^{14}{ }^{15}$ the influence of plasma viscosity and blood fluidity does not seem as important for the microcirculation of eyes with epiretinal membranes, because ERMs are not systemic diseases.

Ultrastructural studies have demonstrated that epiretinal membranes are composed mainly of glial cells that reach the retinal surface via the internal limiting membranes. ${ }^{16}{ }^{17}$ However, it has also been reported that in the eyes with ERMs after retinal detachment surgery, the predominant cell type was the retinal pigment cell. ${ }^{18}$ Although the pathogenesis of ERM formation remains unclear because of the variety of substances or cells which can possibly associated with the formation of ERM, cell proliferations on the retinal surface may lead to the damage of the vasculature in eyes with idiopathic ERMs.

The incidence of posterior vitreous detachment (PVD) in eyes with idiopathic ERMs is variable. ${ }^{19}{ }^{20}$ The posterior vitreous face in eyes without PVD remains firmly attached to the macula, which is pulled forward under anteroposterior traction. In addition to the pathogenesis of ERMs already described, this phenomenon in eyes without PVD may also lead to the damage of the capillary vasculature and result in decreased microcirculation.

We think that the capillary blood flow velocity may be associated with postoperative visual function in eyes with ERMs. However, postoperative visual function can be associated with several factors, such as preoperative visual acuity, duration of symptoms, postoperative nuclear cataract formation, and retinal pigment epithelial disturbances. ${ }^{572122}$ Further investi- gations are required to examine the relation between retinal capillary blood flow of eyes with ERMs and postoperative visual function. It would be of considerable interest to determine whether assessment of the capillary blood flow velocity has any predictive value in the improvement of vision after surgery. ${ }^{921}$

In conclusion, we found a significant reduction in perifoveal retinal blood flow velocity in eyes with ERMs, whether they were idiopathic or secondary. This disturbance of microcirculation may be induced by abnormal retinal vasculature, which is thought to be caused mainly by morphological changes in the retinal surface due to the presence of ERMs. Moreover, the perifoveal blood flow velocity in eyes with ERMs significantly increased after surgery. This shows that the vitreous surgery may be an useful treatment for improving the microcirculation of eyes with ERMs.

1 Appiah AP, Hirose T. Secondary causes of premacular fibrosis. Ophthalmology 1989;96:389-92.

2 Mitchell P, Smith W, Chey T, et al. Prevalence and associations of epiretinal membranes. Ophthalmology 1997;104: 1033-40.

3 Wise GN. Clinical features of idiopathic preretinal macular fibrosis. Am f Ophthalmol 1975;79:349-57.

4 Wise GN, Campbell CJ, Wendler PF, et al. Photocoagulation of vascular lesions of the macular. Am 7 Ophthalmol 1968;66:452.

5 Appiah AP, Hirose T, Kado M. A review of 324 cases of idiopathic premacular gliosis. Am $\mathcal{F}$ Ophthalomol 1988;106: 533-5.

6 Noble KG, Carr RE. Idiopathic preretinal gliosis. Ophthalmology 1982;89:521-3.

7 McDonald HR, Verre WP, Aaberg TM. Surgical management of idiopathic epiretinal membranes. Ophthalmology 1986;93:978-83.

8 Margherio RR, Cox MS, Trese MT, et al. Removal of epimacular membranes. Ophthalmology 1985;92:1075-83.

9 Maguire AM, Margherio RR, Dmuchowski C. Preoperative fluorescent angiographic features of surgically removed idiopathic epiretinal membranes. Retina 1994;14:411-16.

10 Wolf S, Arend O, Toonen H, et al. Retinal capillary blood flow measurement with a scanning laser ophthalmoscope. Ophthalmology 1991;98:996-1000.

11 Barr DB. An appraisal of the accuracy of Littmann's method of determining the real dimension of a retinal object. Acta Ophthalmol Scand 1995;73:1-9.

12 Rassam SMB, Patel V, Brinchmann-Hansen O, et al. Accurate vessel with measurement from fundus photographs: a rate vessel with measurement from fundus p

13 Tanenbaum HL, Schepens CL, Elzneiny I, et al. Macular pucker following retinal detachment surgery. Arch Ophthalmol 1970;83:286-93.

14 Arend O, Wolf S, Jung F, et al. Retinal microcirculation in patients with diabetes mellitus: dynamic and morphological analysis of perifoveal capillary network. Brf Ophthalmol 1991;75: 514-18.

15 Trope GE, Lowe GDO, Ghafour IM, et al. Blood viscosity in proliferative diabetic retinopathy and complicated retinal vein thrombosis. Trans Ophthalmol Soc UK 1983;103:10810 .

16 Smiddy WE, Maguire AM, Green WR, et al. Idiopathic epiretinal membranes: ultrastructural characteristics and clinicopathologic correlation. Ophthalmology 1989;96:81121 .

17 Bellhorn MB, Friedman AH, Wise GN, et al. Ultrastructure and clinicopathologic correlation of idiopathic preretinal macular fibrosis. Am 7 Ophthalmol 1975;79:366-73.

18 Clarkson JG, Green WR, Massof D. A histopathologic review of 168 cases of preretinal membrane. Am $\mathcal{f}$ Ophthalreview of $1977 ; 84: 1-17$.

19 Heilskov TW, Massicotte SJ, Folk JC. Epiretinal macular membranes in eyes with attached posterior cortical vitreous. Retina 1996;16:279-84.

20 Hirokawa J, Jalkh AE, Takahashi M, et al. Role of the vitreous in idiopathic preretinal macular fibrosis. Am f Ophthalmol 1986;101:166-9.

21 Rice TA, DeBustros S, Michels RG, et al. Prognostic factors in vitrectomy for epiretinal membranes of the macula. Ophthalmology 1986;93:602-10.

22 Michels RG. Vitrectomy for macular pucker. Ophthalmology 1984;91:1384-8. 